Revista de Derecho

de la Pontificia Universidad Católica de Valparaíso

XXXIV (Valparaíso, Chile, ${ }^{\text {er }}$ Semestre de 2010)

[pp. 459 - 474]

\title{
¿ES POSIBLE SANCIONAR LAS LESIONES Y EL HOMICIDIO EN CONCURSO IDEAL?
}

[“Can Damages and Manslaughter be Punished in an Ideal Agreement?”]

\author{
Claudio Prambs* \\ Universidad Mayor, sede de Temuco, Chile \\ Universidad San Sebastián, sede de Osorno, Chile
}

\begin{abstract}
RESUMEN
El trabajo plantea la tesis de que puede sancionarse un delito de homicidio simple consumado en concurso ideal con un delito de lesiones consumadas. Para Chile, este novedoso planteamiento tiene una justificación criminológica y político-criminal, cual es la frecuencia estadística de estos hechos y la baja penalidad del homicidio simple, en el límite inferior de la pena, de modo que, en ciertos casos (inexistencia de agravantes o compensación de ellas, existencia de dos o más atenuantes o de una atenuante muy calificada e informe pre-sentencial favorable) el autor puede no recibir una pena proporcionada a la importancia del bien jurídico que destruyó, y puede cumplir la pena bajo el régimen de libertad vigilada; por su parte, los cómplices
\end{abstract}

\begin{abstract}
This work states the thesis that voluntary manslaughter can be punished in concurrence of a personal injuries crime. In the case of Chile, this original statement is based on criminological and political-criminal grounds, which are the statistical frequency of these events and the minor punishment for voluntary manslaughter, in the lower limit of the punishment, so that in certain cases (non existence of aggravating circumstances or the compensation of them, existence of two or more extenuating circumstances or of a very solid extenuating circumstance and favorable pre-sentence report) the wrongdoer may not receive a punishment proportional to the importance of the legal rights infringed and can serve sentence under parole; on the other
\end{abstract}

* Egresado de Derecho en la Universidad Católica de Valparaíso. Licenciado en Derecho por la Universidad de Salamanca, España. Profesor de Derecho penal en la Universidad Mayor, sede de Temuco, y en la Universidad San Sebastián, sede de Osorno. Dirección postal: Bernardo O’Higgins 485, of. 407, Osorno. Teléfono: 64/ 319847. Correo electrónico: Claudio65@web.de. 
tienen un régimen penológico que ni siquiera los hace candidatos a la prisión preventiva y menos aún a la privación de libertad en el cumplimiento de la pena.

Palabras clave: Delito de homicidio simple - Delito de lesiones - Concurso ideal. hand, accessories have a punishment regime that doesn't even make them eligible to have pre-trial detention and even less to be deprived of liberty while they are serving sentence.

KEYWORDS: Voluntary manslaughter - Misdemeanor assault - Concurrence of criminal offenses.

\section{INTRODUCCIÓN}

\section{El problema y el objeto de estudio.}

Averiguaremos si, y en qué medida, podemos justificar dogmática y político-criminalmente el castigo del homicidio simple aplicando un concurso ideal con el delito de lesiones, que normalmente acompaña a aquel, asignando la pena legal principal abstracta de presidio mayor en su grado medio, de conformidad con la regla penológica de agravación contenida en el artículo 75 inciso $1^{\circ}$ del Código Penal chileno. En consecuencia, el objeto de nuestro trabajo es acotado sólo a este tema, y no abarca las consecuencias que la respuesta positiva pueda irradiar hacia otros problemas.

\section{Presupuestos metodológicos.}

Dada la naturaleza y extensión de este trabajo, hemos de partir de ciertos presupuestos metodológicos y posturas dogmáticas que habremos de dar por sabidas.

Damos por aceptado que no es político criminalmente correcto, porque vulnera la axiología jurídica ${ }^{1}$ que el homicidio simple tenga penalidad tan baja, en el tramo inferior (presidio mayor en su grado mínimo), lo que permite a sujetos que pueden CP.) o una muy calificada (artículo 68 bis) y obtengan un informe pre-sentencial satisfactorio obtener el beneficio de libertad vigilada (artículo 15 de la Ley No 18.216), es decir, no permanecer ni un día privados de libertad, especialmente si no se decreta su prisión preventiva ${ }^{2}$.

${ }^{1} \mathrm{Y}$ en esto concuerda la doctrina patria; al respecto, la versión refundida de los materiales de discusión de las unidades $1^{\text {a }}$ a $9^{\text {a }}$ de la parte especial del "Anteproyecto de Código Penal”, elaborados por los profesores Jean Pierre Matus Acuña y Héctor Hernández Basualto, con las observaciones recibidas y las conclusiones arribadas en las sesiones del Foro Penal, dan cuenta que se acordó castigar el homicidio simple con reclusión mayor en su grado medio, es decir, con pena de 10 años y un día a 15 años.

${ }^{2}$ No existe constancia alguna en las "Actas de la Comisión Redactora del Código Penal" chileno del motivo que indujo a los comisionados a apartarse del modelo 
Nuestra investigación parte del reconocimiento que la doctrina y la jurisprudencia aprecian un concurso aparente de leyes penales entre lesiones y homicidio consumado, sea que apliquen el principio de subsidiariedad tácita o el de consunción; de manera que surge una pregunta ineludible: ¿Existe algún penalista o fallo que haya negado la relación de concurso aparente entre las lesiones y el homicidio? Su respuesta afirmativa -la cual adelanto ${ }^{3}$ - nos permitirá avanzar en nuestra tesis. Pero no basta con constatar alguna disidencia (las cuales siempre existen en la Ciencia del Derecho, por ser una disciplina que pertenece al mundo de los valores, ergo, especulativa), sino que lo importante es ahondar en los fundamentos de la doctrina del concurso aparente, pues si ellos son compatibles con nuestra tesis, la fortalecerán.

Otro de los presupuestos de nuestra investigación, siguiendo la moderna y mayoritaria doctrina penal, es ubicar el concurso aparente de leyes dentro de la teoría de los concursos en general, y aquella, a su vez, la situamos sistemáticamente dentro de la teoría de la determinación de la pena ${ }^{4}$. Desechamos, así, las antiguas visiones dogmáticas que ubican el concurso aparente de leyes dentro de la teoría de la interpretación de la ley penal, separada de los "verdaderos concursos", y éstos dentro de la teoría de las formas de aparición del delito".

Esta opción sistemática es funcional a nuestros propósitos, porque de acuerdo a ella el problema del concurso es un asunto exclusivo de determinación de la pena, de manera que si su aplicación (del concurso aparente) conlleva algún déficit punitivo (que es la base de nuestra tesis), debe optarse por la regla general o régimen común, que es el concurso ideal ${ }^{6}$. Y ello es

español de 1850, que asignaba al homicidio simple la pena de reclusión de doce a veinte años.

${ }^{3}$ Dice Matus Acuña, Jean Pierre, La ley penal y su interpretación (Santiago, Editorial Jurídica Congreso, 1994), p. 174, lo siguiente: “[...] el acuerdo sobre la naturaleza del concurso aparente de leyes se limita sólo a su existencia, pues en cuanto a los casos que contiene, sus límites y los principios de solución, las opiniones son tan dispares que Stratenwert lo ha llegado a calificar de una cuestión "discutida y sin ninguna esperanza“. Este escepticismo, se puede reflejar en las consideraciones de Nino [...], quien afirma que la distinción entre concurso aparente y concurso ideal es insostenible, que aquel es un "cajón de sastre "de la dogmática y que "lo cierto es que los casos desarrollados por la dogmática como de concurso aparente de leyes son, en su mayoría, casos de verdadera concurrencia [...]".

${ }^{4}$ Así, entre otros, Bockelmann, Paul - VolK, Klaus, Strafrecht. Allgemeine Teil (4a edición, München, 1987), p. 257; y Baumann, Jürgen - Weber, Ulrich, Strafrecht. Allgemeine Teil. Ein Lehbuch (9a edición, Bielefeld, 1985), p. 600.

${ }^{5}$ Sobre estas visiones, Jescheck, Hans-Heinrich, Lehrbuch des Strafrechts. Allgemeine Teil (4a edición, Berlin, 1988), pp. 665 ss.

${ }^{6}$ Sobre la excepcionalidad del concurso aparente y sobre el concurso ideal como 
absolutamente consecuente con el problema de determinación de la pena, que reviste una dimensión político criminal esencial ${ }^{7}$ visión, ésta, que es el móvil de nuestra tesis.

Para justificar nuestra postura, partimos de la concepción del dolo compuesto sólo por el elemento cognoscitivo, es decir, como conocimiento de los elementos típicos objetivos, no siendo la voluntad elemento del dolo, ni ubicada en la teoría del injusto típico, sino ella que es el contenido, único y exclusivo, del juicio de culpabilidad, ergo, sita en la categoría dogmática de la culpabilidad penal ${ }^{8}$. De esta forma, eliminamos cualquier tacha que se nos pueda formular por infracción al supuesto factor "intencionalidad ", que alguna doctrina penal de nuestro país utiliza para diferenciar el delito de homicidio del delito de lesiones'; y que la doctrina de la Sala Penal de nuestra Corte Suprema asume, a nuestro juicio equivocadamente, para analizar los supuestos de "homicidio preterintencional"10.

Por último, nuestra referencia dogmática principal es la doctrina alemana; ello por tres razones: primera, la teoría del concurso nació en dicho país y presenta un desarrollo que no tiene parangón en ningún país de nuestro entorno cultural; segunda, recurrir a las fuentes dogmáticas peninsulares nada de relieve aporta, porque un atento estudio de ellas revela que nada

régimen común: MAYER, Max Ernst, Derecho Penal. Parte general (traducción y notas de Politoff, Sergio, Montevideo - Buenos Aires, Editorial B de F, 2007), pp. 619 ss.

${ }^{7}$ Sobre la función político criminal de la pena, Quintero, Gonzalo - Morales, Fermín - Prats, José, Manual de Derecho penal. Parte general (Pamplona, Editorial Aranzadi, 1999), p. 737.

${ }^{8}$ Sobre esta concepción: Prambs, Claudio, El tipo de culpabilidad en el Código Penal chileno: Una visión sistemática, normativa y positiva (Santiago, Editorial Metropolitana, 2005), pp. 10 ss.; también, PramBs, Claudio, ¿Qué es el dolo penal y qué es el error penal? en Revista de Derecho y Ciencias Penales, 10 (Universidad San Sebastián, 2008), pp. 83-101.

${ }^{9} \mathrm{Al}$ respecto, Novoa Monreal, Eduardo, Delito de homicidio y la intención de matar, en Revista de Ciencias Penales, 8 (1945), pp. 183 ss.

${ }^{10}$ En sentencia de fecha 17 de agosto de 2005 (en Gaceta Jurídica, 302, pp. 180 ss.), recaído en un caso de lesiones dolosas que provocaron la muerte de la víctima, declaró que "la figura del delito preterintencional no se encuentra definida por nuestro derecho positivo, pero si por la doctrina, estableciéndose que esta figura se presenta cuando el evento típico supera la voluntad de realización-el dolo-del hechor, provocando que el daño ocasionado con la acción sea cualitativamente mayor que el buscado o aceptado por éste". Sin embargo, lo importante de este fallo, para nuestra tesis, es que sanciona por un concurso ideal de delitos de lesiones (dolosas) y homicidio (culposo), recurriendo al artículo 75 para aquilatar el quantum de la pena, siguiendo así una tendencia histórica que había iniciado en 1960, en fallo dictado en un caso de aborto doloso seguido de muerte culposa [Revista de Ciencias Penales, tercera época, 19 (enero abril, 1960) 1]. 
original, en esta materia, se ha creado, a lo que debe agregarse el verdadero desacierto regulativo que contiene el artículo 8 del Código Penal de 1995, que oscurece más este problema, de suyo complejo y; por último, nuestra doctrina casi unánime bebe de la fuente hispánica, de manera que le afecta el mismo reparo ${ }^{11}$.

\section{SOLUCIÓN DEL PROBLEMA}

\section{La justificación criminológica y político criminal.}

Chile es un país que posee un alto índice de homicidios. Comparativamente, existen más homicidios en Chile que en Nueva York, pues en el año 2004 en Chile hubo 8 homicidios por cada 100 mil habitantes; en cambio, en la gran manzana sólo hubo 7 por cada 100 mil habitantes ${ }^{12}$, lo que justifica no amenazar este delito con penas tan bajas, puesto que el valor instructivo del tipo penal a la población no cumple su fin disuasivo o de prevención general ${ }^{13}$.

Comparativamente, la pena del homicidio simple en el Código Penal chileno es inferior a la de los países de nuestro entorno cultural, y ello es tan evidente que en el "Anteproyecto de Código Penal" de 2005 se adjudica al homicidio simple la pena de 10 años y un día a 15 años de reclusión. En el escenario europeo, España sanciona este homicidio con pena privativa de libertad de 10 a 15 años (artículo 138) y en Alemania, de 5 años a presidio perpetuo (artículo 212); en la América hispana, en Argentina se sanciona de 8 a 25 años (artículo 79); Perú, de 6 a 20 años (artículo 106); Bolivia, de 5 a 20 años (artículo 251); Ecuador, de 8 a 12 años (artículo 449); Venezuela, de 12 a 18 años (artículo 407); y México, de 12 a 24 años (artículo 307).

${ }^{11}$ De especial utilidad es el trabajo monográfico, directamente atingente a nuestro tema, pero que contiene, precisamente, la tesis que combatimos, de SснмітT, Rodolf. Vorsätzliche Tötung und Vorsätzliche Körperverletzung: Eine systematische Untersuchung im Anschlu $\beta$ an BGHSt 16, 122, aparecido en la revista especializada Juristische Zeitung (1962), pp. 389 ss.

${ }^{12}$ Disponible en: http://www.airelibrechile.cl/noticias/mitos.html [consulta realizada el día 10 de julio de 2009]. Sólo en el gran Santiago, durante el año 2007, hubo 610 homicidios, según datos recopilados en las fiscalías de la Región Metropolitana, disponible en: http://ciperchile.cl/2008/02/07/radiografia-del-crimen-comodonde-y-por-que-se-mata-en-el-gran-santiago/ [consulta realizada el día 10 de julio de 2009].

${ }^{13}$ Sobre esta función típica: Roxin, Claus, Derecho penal. Parte general. Fundamentos. La estructura de la teoría del delito (traducción y notas de Luzón Peña, D. y otros, Madrid, Civitas, 1997), I, pp. 127 ss. 


\section{La justificación práctica.}

Conforme lo reconoce nuestra doctrina penal, el tiempo que media entre las lesiones y la muerte no tiene relevancia especial para apreciar un delito de homicidio ${ }^{14}$; de manera que, en la práctica, los fiscales se encuentran ante la duda de formalizar, en casos en que aún la muerte no se produce, pero es previsible que ocurra, por homicidio frustrado ${ }^{15}$, o bien por lesiones ${ }^{16}$, o bien por un concurso ideal entre ambos delitos ${ }^{17}$.

El real problema ocurre si, producida cualquiera de las dos primeras formalizaciones, con posterioridad la víctima muere como consecuencia de las lesiones, puesto que, en puridad, nuestro procedimiento penal no conoce el instituto que la práctica ha dado en llamar "reformalización de la investigación"; por ello, muchos jueces, con razón, no la aceptan. Frente a ello, y para evitar un trato beneficioso para el hechor, en supuestos en que la muerte sea pronosticada por los médicos como probable, no queda otro camino que formalizar por lesiones y por homicidio, en concurso ideal (dos delitos), no siendo ningún obstáculo que la muerte aún no ocurra (para formalizar no se necesita realidad ni prueba alguna de los hechos comunicados), puesto que puede suceder a futuro como consecuencia de las lesiones. De esta forma, el sujeto queda correctamente formalizado; y si la muerte no ocurre será acusado sólo por lesiones o en concurso ideal con homicidio frustrado; en caso contrario, por concurso ideal entre lesiones dolosas consumadas y homicidio doloso consumado (según nuestra tesis).

\section{Relación entre lesiones y homicidio. Las distintas posiciones doctrina-} les.

La doctrina abrumadoramente mayoritaria sostiene que entre lesiones dolosas consumadas y homicidio doloso consumado existe un concurso aparente de leyes. Sin embargo, las discrepancias se suscitan a la hora de decidir cuál es el principio que debe solucionar este conflicto de normas.

\footnotetext{
${ }^{14}$ Así, expresamente, Politoff, Sergio - Grisolía, Francisco - Bustos, Juan, Derecho penal, pp. 77-78; y GARRIDo MonTt, Mario, Derecho penal. Parte especial (Santiago, Editorial Jurídica de Chile, 2001), III, p. 38, quien dice: "Es frecuente que la acción matadora del autor no se materialice de inmediato en el deceso de la víctima, deceso que sobreviene con posterioridad. Normalmente, la referida circunstancia no modifica la relación existente entre la acción y el resultado, de suerte que si la muerte sobreviene días y aún meses más tarde, siempre se estará ante un homicidio“.

${ }^{15}$ Cousiño MaC IVER, Luis, El dolo eventual en la dogmática chilena, en Revista de Ciencias Penales, 27 (1968) 2, pp. 115 ss.

${ }^{16}$ Garrido Montt, Mario. Derecho penal, cit. (n. 14) pp. 42-43.

${ }^{17}$ Politoff, Sergio - Grisolía, Francisco - Bustos, Juan, Derecho Penal, pp. $69-70$.
} 
Para unos pocos en Alemania, la solución se encuentra en el principio de especialidad ${ }^{18}$; para otros, la solución la da el principio de subsidiariedad tácita ${ }^{19} ; y$, en nuestro país, la totalidad de la doctrina ${ }^{20}$, un importante grupo de profesores alemanes ${ }^{21}$, y la mayoría de la doctrina española ${ }^{22}$, ven la solución en el principio de consunción.

Otra parcela doctrinaria y jurisprudencial, no entiende el problema de igual forma, sino que utilizando, primero, la concepción de Carrara ${ }^{23}$, sobre la significación del fin del agente en la especialidad de los delitos y, posteriormente, la concepción del dolo con dos elementos (conocimiento y voluntad), llegan a la muy discutible conclusión de que si el sujeto tenía intención (voluntad) de matar sólo puede ser sancionado por homicidio, porque no había voluntariedad (dolo) de lesionar, es decir, utilizan el concepto de animus necandi para diferenciar el homicidio de las lesiones, asumiendo, de esta forma, que no estamos ante un problema de concurso,

${ }^{18}$ Por todos, JaKoBs, Günther, Strafrechts. Allgemeine Teil. Die Grundlagen und die Zurechnungslehre (2a edición, Berlin, 1991), pp. 11 ss.; Sснмітт, Rodolf, Vorsätzliche Tötung und Vorsätzliche Körperverletzung, cit. (n. 11), p. 391.

${ }^{19}$ Por todos: SchÖnKe, Adolf - SCHRÖDER, Horst - STREe, Walter, Strafgesetzbuch Kommentar (24a edición, München, 1991), $\$ \$ 52,105,119,120$, quienes siguen a Binding, Karl, Handbuch des Strafrechts (Leipzig, 1885), I, p. 358, para quien el delito de lesiones sólo abarcaría aquellas no destinadas a cometer homicidio. Si las lesiones van dirigidas a matar habría homicidio y no lesiones, que resultan subsidiarias respecto de aquel. Como se puede apreciar, Binding poco explica. En España, Del Rosal, Juan, Lecciones de Derecho Penal (Valladolid, 1953), p. 237; Rodríguez Devesa, José María, Derecho penal español. Parte general (1a edición, reimpresión, Madrid, 1971), p. 153; Mir Puig, Santiago, Derecho penal. Parte general (3a edición, Barcelona, 1990), p. 739.

${ }^{20}$ Por todos: Matus AcuñA, Jean Pierre, Comentario preliminar a los artículos 74 y 75 del Código (Santiago, Editorial Jurídica de Chile, 2002), I, pp. 383-398, especialmente, pp. 392 y 393.

${ }^{21}$ JesCHECK, Hans-Heinrich, Lehrbuch, cit. (n. 5), p. 669 ss. Binding, Karl, Handbuch, cit. (n. 19), pp. 364 ss.; MAYER, Max Ernst. Der allgemeine Teil des Deutsche Strafrechts. Lehrbuch (Heidelberg, 1915), p. 503; HoNIG, Richard, Straflose vorund Nachtat (Leipzig, 1927), pp. 66 ss. y 113; MEZGER, Edmund. Strafrecht. Ein Lehrbuch (3a edición, Berlin - München, 1949), pp. 472 ss.

${ }^{22}$ Puig Peña, Federico. Colisión de normas penales: concurso aparente de leyes punitivas (Barcelona, 1955), p. 68; en el mismo sentido, Rodríguez Mourullo, Gonzalo, Derecho penal. Parte general (Madrid, 1978), p. 116.

${ }^{23}$ Carrara, Francesco, Programma del corso di Diritto criminale (Lucca, 1869), parágrafos 152 y 153. En el parágrafo 2014, se lee lo siguiente: "La causa de delinquir, he dicho varias veces, no se debe tomar como condición esencial constitutiva de la especialidad de los delitos; porque la objetividad jurídica que da la esencia al maleficio está en el derecho atacado y no en el bien o ventaja que se proponía conseguir el delincuente“. 
sino ante un problema de intencionalidad, un problema de subjetividad de la conducta ${ }^{24}$.

Por último, una tercera visión doctrinaria y jurisprudencial, partiendo de la concepción hegeliana, asume que la voluntariedad es un elemento de la acción, y de esta forma concluyen que si no había voluntad de lesionar, sino que de matar, no puede haber conducta lesiva, sino que sólo conducta matadora, ergo, el sujeto no puede ser sancionado por conductas que no ha llevado a cabo, como es la de lesionar ${ }^{25}$.

\section{Toma de postura.}

a) Los principios de solución. Nuestra postura en esta disputa no puede ser neutral, sino que funcional, considerando que los principios de subsidiariedad tácita y el de consunción tienen distinto fundamento; el primero, se basa en una relación lógica de las normas, ergo, permanente y absoluta; el segundo, en cambio, en una relación valorativa, ergo, contingente y relativa. Será, en consecuencia, funcional a nuestra tesis adoptar el principio de la contingencia, ya que permite afirmar nuestra tesis sin recibir objeciones insalvables derivadas de la lógica.

Sin todavía entrar al problema de la existencia o no de un concurso aparente de leyes, partamos por posicionarnos con respecto a cuáles son los principios de solución que, estimamos, deben ser inmediatamente eliminados. Al respecto, y concordando con nuestra doctrina unánime, creemos que debe desecharse el principio de subsidiariedad tácita, puesto que, como bien sostienen Mayer ${ }^{26}$ y Honig ${ }^{27}$, el presupuesto del mismo es una pluralidad de conductas, realizadas una tras la otra, lo que hecha por tierra la unidad de acción, requisito sine qua non del concurso aparente de leyes penales; $y$, por ello, Mayer ${ }^{28}$, en lo que lo siguen varios penalistas de antaño y hogaño, sólo reconocía dos principios del concurso aparente: la especialidad y la consunción.

Descartando la especialidad, porque se basa en una relación lógica, que

${ }^{24}$ Sobre esta concepción: Novoa Monreal, Eduardo, Delito de homicidio, cit. (n. 9), pp. 183 ss.

${ }^{25}$ Para la crítica de esta visión, disfuncional en nuestro Código Penal: Prambs, Claudio, El tipo de culpabilidad, cit. (n. 8), pp. 25 ss.

${ }^{26}$ MaYer, Max Ernst, Derecho penal, cit. (n. 6), pp. 620 y ss.

${ }^{27}$ Honig, Richard, Straflose vor- und Nachtat, cit. (n. 21), pp. 51 ss.

${ }^{28}$ Mayer, Max Ernst, Derecho Penal, cit. (n. 6), pp. 622 ss. En el mismo sentido, Etcheverry, Alfredo, El concurso aparente de leyes penales (Santiago, Editorial Jurídica de Chile, sin fecha), pp. 15 ss., 45 ss. y 99; El mISmo, Derecho penal. Parte general (3a edición, Santiago, Editorial Jurídica de Chile, 1998), II, p. 123; y CurY, Enrique, Derecho penal. Parte general ( $7^{\text {a }}$ edición ampliada, Santiago, Ediciones Universidad Católica de Chile, 2005), p. 668. 
no concurre entre lesiones y homicidio (según lo reconoce la casi totalidad de la doctrina), sólo nos queda por abordar el principio de consunción.

Según Sauer" "es el más confuso caso de concurso de leyes“. Y la tesis ampliamente mayoritaria incurre en una inconsecuencia sistemática consistente en aplicar las reglas del concurso aparente a casos en que lo protegido son bienes jurídicos diferentes, como la vida (homicidio) y la integridad corporal o salud individual (lesiones) ${ }^{30}$, en circunstancias que para apreciar este tipo de concurso se exige identidad de bien jurídico ${ }^{31}$; y sólo por incurrir en este defecto lógico-sistemático, la desechamos.

b) Inexistencia de concurso aparente. Hemos de partir de una afirmación que, si bien no es decisiva, es decidora: el concurso aparente de leyes no está regulado en nuestro Código Penal, y deliberadamente no fue normado en la gran reforma penal alemana, que comenzó en el año 1954 y culminó con la promulgación del Código de 1 de enero de 1975, porque el parecer de los profesores que formaron las comisiones fue que la materia no ha sido suficientemente aclarada por la Ciencia penal ${ }^{32}$. Y si aún no existen principios científicamente afianzados sobre el concurso aparente de leyes, tal doctrina no puede ser utilizada como fundamento de la relación existente entre lesiones y homicidio [artículo 342, letra d), del Código Procesal Penal chileno], por no cumplir con el requisito del afianzamiento científico que exige el artículo 297 del mismo.

Existen varios criterios para distinguir el concurso aparente del ideal ${ }^{33}$.

${ }^{29}$ WilHeLm, Allgemeine Strafrechtslehre (3a edición, Berlin, 1955), p. 229.

${ }^{30}$ Sobre la falta de identidad de ambos bienes jurídicos, véase la sentencia del Tribunal Supremo español, de 4 de julio de 1983 (Repertorio Aranzadi,No 4020).

${ }^{31}$ En Alemania, Merkel, Adolph, Handbuch des deutschen Strafrechts (Berlin, 1877), IV, pp. 225-226; HabermaAs, Frank, Die Ideale Konkurrenz der Delikte (Sttutgart, 1882), p. 1 ss.; Отто, Harro. Grundkurs Strafrecht (4a edición, Berlin, 1992), pp. 311 ss.; SCHÖnKe, Adolf - Schröder, Horst - Stree, Walter, Strafgesetzbuch Kommentar, cit. (n. 19), pp. 112 ss.; SCHMIDHÄUSER, Eberhard, Strafrecht. Allgemeine Teil. Lehrbuch (Tübingen, 1975), pp. 18-32; y WeSSELS, Johannes, Strafrechts. Allgemeine Teil (23a edición, Heidelberg, 1993), p. 252.

${ }^{32}$ Por más de veinte años los doctores en Derecho penal en Alemania se dedicaron al estudio y elaboración del Código, y concluyeron que no debía regularse en la parte general el concurso aparente de leyes y, en la parte especial, sólo debían introducirse unas pocas cláusulas de subsidiariedad expresa para solucionar los casos más conflictivos. Deutscher Bundestag 5. Walhperiode 1965-1969, Protokolle des Sonderausschu für die Strafrechtsreform, pp. 903 ss.

${ }^{33}$ Los primeros exponentes fueron Wächter (1825), Bauer (1833), Abegg (1836), Köstlin (1855), y quien lleva el título de fundador de la teoría del concurso aparente es Adolf Merkel (1871 y 1877); sobre el tema, GEERDS, Friederich, Zur Lehre von der Konkurrenz im Strafrecht (Hamburg, 1961), pp. 54 ss. En la doctrina española, sólo se aprecia un aporte a la teoría, por medio de obras monográficas, a partir de 1986 
Reinhard Frank los distinguió, claramente, por medio de la "fórmula de la necesidad", diciendo que para estimar concurso aparente de leyes en contra de uno ideal la concurrencia habría de desprenderse necesariamente y no producirse de manera contingente, casual o accidental en el caso concreto ${ }^{34}$. De esta forma, no existiría obstáculo alguno en afirmar que las lesiones no son necesarias para provocar la muerte, si comprobamos que, en la práctica, no todas ellas son mortales, y que ésta puede producirse por los llamados "medios morales", que no causan lesión alguna, no obstante ser idóneos para matar. Bajo esta denominación se abarcan todos los medios que no son físicos, ya consistan en provocar una impresión síquica sobre la víctima (miedo o impresión súbita), ya valiéndose de un procedimiento puramente intelectual, como la palabra ${ }^{35}$; o por los denominados "medios indirectos", como hacer trabajar dura o prolongadamente a una persona, etc. ${ }^{36}$.

Ingeborg Puppe, quien sigue al creador de la teoría del concurso de leyes, Adolf Merkel, sostiene que existe concurso aparente solamente cuando entre las leyes en juego existe especialidad, es decir, cuando ambas descripciones legales tienen los mismos elementos, pero una tiene, además, uno o más adicionales que la distinguen. Esta renombrada doctora ${ }^{37}$ sólo aprecia concurso de leyes en los supuestos que la doctrina patria y peninsular cobijan bajo el principio de especialidad, que no ampara la relación lesiones-homicidio. Según ella, en todos los casos que se presentan por la doctrina mayoritaria bajo los principios de subsidiariedad tácita y consunción (no olvidemos que la doctrina casi unánime presenta el concurso entre lesiones y homicidio bajo estos principios), estamos ante un concurso ideal de delitos, y no ante un concurso de leyes penales. Dice Puppe: "La distinción hecha por la doctrina tradicional entre concurso ideal por un lado, y subsidiariedad y consunción por otro, no sólo es difusa, vaga y discutible, sino, sobre todo, desconcertante y completamente inútil”38.

(Sanz), Peñaranda (1991), Cuerda (1992), Cid (1994) y García Albero (1995).

${ }^{34}$ En el mismo sentido, Reichardt, Carl, Kurzgefaßtes Lehrbuch des deutschen Strafrechts (Karlsruhe, 1912), p. 211. Por su parte, el Tribunal Supremo Federal alemán sigue la misma doctrina en sentencia de fecha 28 de junio de 1961, y utiliza el concepto de "delito de tránsito necesario". Por todos, Frank, Reinhard, Das Strafgesetzbuch für das Deutsche Reich (18a edición, Tübingen, 1931), $\$ 73$, VII, 3.

${ }^{35}$ Politoff, Sergio - Grisolía, Francisco - Bustos, Juan, Derecho penal, pp. 61-62.

${ }^{36}$ Antolisei, Francesco, Manuale di Diritto penale. Parte speciale (4ª edición, Milano, 1960), I, p. 38.

${ }^{37}$ A quien se ha alabado por realizar un extraordinario aporte a la teoría concursal y, en especial, a la distinción entre concurso ideal y concurso aparente; así, GÖsSEL, Karl, Besprechung über I. Puppes Idealkonkurrenz und Einzelverbrechen, en Goltdammer Archiv für Strafrecht (1981), pp. 135 ss.

${ }^{38}$ Puppe, Ingeborg, Exklusivität von Tatbeständen, en Juristische Ausbildung 
c) No afectación de los fundamentos del concurso de leyes. Para que nuestra tesis tenga validez, no puede pasar por alto, ignorando o afectando, los fundamentos del concurso aparente, puesto que éste sigue teniendo vigencia para casos no comprendidos en la relación lesiones homicidio.

El análisis de la dogmática nos permite identificar los siguientes fundamentos que se asignan a la teoría del concurso de leyes penales: no violación del principio del non bis in ídem (fundamento del principio de especialidad) y aplicación del principio de insignificancia (que funda el principio de consunción) ${ }^{39}$. Nosotros agregamos la no violación al principio de igualdad constitucional por medio del expediente de sancionar a los

(1984), pp. 160-162, quien califica como fraude de etiquetas a los principios de subsidiariedad y consunción, respecto del concurso ideal. Especialmente clara es con respecto a los casos en que la ley desplazada por los tradicionales principios de consunción y subsidiariedad tiene mayor penalidad que la desplazante. En tales casos, la doctrina tradicional trata de salvar esta inconsecuencia aplicando parte de la pena de la ley desplazada, lo que implica aceptar las reglas del concurso ideal, es decir, concluye ella, estamos aplicando las reglas del concurso ideal y no aparente, lo que demostraría el acierto de su tesis y el desacierto de la contraria. En nuestro medio, esta es la inconsecuencia en que incurre la doctrina cuando analiza el supuesto del homicidio frustrado y las lesiones, caso en que aprecia un concurso ideal de delitos y no un concurso aparente por consunción o subsidiariedad tácita (por todos, Politoff, Sergio - Grisolía, Francisco - Bustos, Juan, Derecho Penal, pp. 69-70), a quienes cito textual para corroborar lo que decimos, y nuestra tesis: "Esta pluralidad de bienes jurídicos de distinta entidad (heterogéneos) comprometidos, en que no cabe absorber el uno en el otro, configuran pluralidad de delitos a través de un hecho único, que es precisamente la noción que corresponde al llamado concurso ideal (heterogéneo). Esta forma de concurso ideal llamada heterogénea propia es el esquema clásico del concurso ideal y nadie ha discutido entre nosotros que tenga cabida dentro del sistema del artículo 75 ". Si ellos reconocen que la vida y la integridad corporal son bienes heterogéneos, que no pueden absorberse uno a otro, estamos ante una pluralidad de delitos a través de un hecho único, es decir, ante un concurso ideal, que es, precisamente, la tesis de nuestro trabajo. En el mismo sentido: Bullemore, Vivian - Mackinnon, John, Curso de Derecho penal. Parte especial (2a edición, Santiago, Editorial LexisNexis, 2007), III, p. 22, dicen: "En cuanto a la presunta existencia de un concurso aparente de leyes penales [...] tal tesis debe descartarse [...] por la sencilla razón que el principio de absorción, único posiblemente rector de esta situación, no es aplicable. En efecto, las lesiones graves no pueden absorber el ilícito de un homicidio frustrado, relacionado con un bien jurídico de mayor entidad como es la vida; ni el ilícito del homicidio frustrado puede absorber el de las lesiones graves, ya que éstas no acompañan, regularmente, de acuerdo a la experiencia de la vida, los intentos de homicidio: no son inherentes a ellos, sino que importan un desvalor autónomo, un atentado independiente contra la integridad física“.

${ }^{39}$ Matus Acuña, Jean Pierre, Comentario preliminar, pp. 383-398, especialmente, pp. 388 y 389. 
autores de homicidio simple en concurso ideal con un delito de lesiones, y no así a los autores de parricidio, asesinato e infanticidio.

De esta manera, sólo nos queda por justificar la aplicación del principio de insignificancia y la no afectación del principio de igualdad desde que ya hemos descartado que las relaciones lesiones - homicidio se funden en el principio de especialidad.

d) La no afectación del principio de igualdad constitucional. Si el principio de igualdad constitucional, contemplado en el artículo 19 No 2 CPol. chilena, se refiere a la igual aplicación de la ley y no implica una prohibición general de un trato desigual, sino que contiene una prohibición de arbitrariedad o el hacer diferencias arbitrarias en la aplicación de la ley penal, la afectación de la garantía pasa por comprobar que la discriminación no tiene justificación ética o racional alguna ${ }^{40}$.

La igualdad ante la ley, ha resuelto el Tribunal Constitucional, "[...] presupone que se trate en forma igual a quienes son efectivamente iguales, y sólo a ellos, y en forma desigual a quienes no lo sean. Ahora, si se hacen diferencias, pues la igualdad no es absoluta, es necesario que ellas no sean arbitrarias $[\ldots] "$... 41 .

Partiendo es esta premisa, no vemos afectación alguna al principio de igualdad en la aplicación de la ley penal si hemos de sancionar en concurso a todos los partícipes en homicidios simples violentos; afectación existiría si sólo a algunos de ellos los sancionáramos sin concurso y a otros en concurso. Y la explicación racional no es otra que la necesidad dogmática y político criminal de imponer a los partícipes en homicidios simples penas justas.

e) La no afectación al principio de insignificancia. El juicio de insignificancia, de intensidad criminal o, para otros, de prohibición de valoración doble ${ }^{42}$ de los tipos en juego, alude a la comparación de la intensidad relativa entre ellos ${ }^{43}$. La consunción consiste en la fagocitosis que realiza el tipo que contiene el injusto mayor respecto del que tiene el injusto menor, es decir, se trata de un juicio cuantitativo de superioridad - inferio-

${ }^{40}$ Corte Suprema, recurso de inaplicabilidad, de 25 de noviembre de 1970, en Revista de Derecho y Jurisprudencia, 67, sec. 1º, p. 530.

${ }^{41}$ Sentencia del Tribunal Constitucional, rol No 219, de 31 de julio de 1995, considerando $17^{\circ}$.

${ }^{42}$ Etcheverry, Alfredo. Derecho Penal, p. 125.

${ }^{43}$ Matus Acuña, Jean Pierre. "Comentario preliminar “, p. 392. Nos parece contradictorio afirmar, como lo hace Matus, que el principio de insignificancia no tome el tipo más grave como preferente, puesto que, precisamente, tal principio implica lo contrario. Creemos, por ello, que es mejor utilizar el principio de ponderación penal para referirse a este tema, tal como lo hace, por ejemplo, Etcheverry, Alfredo. Derecho penal, pp. 126-127. 
ridad. Y esta relación sólo puede ser establecida por el monto penológico de los tipos en juego, conforme lo dispone el dogmáticamente indiscutible artículo $3 \mathrm{CP}$., pues de lo contrario la valoración no sería lógico-sistemática, sino que arbitraria o basada en criterios extra-penales.

Conforme a ello, el principio puede operar cuando ninguna parte del injusto del hecho quede sin respuesta penal, y si no es así habrá que declarar la existencia de un concurso de delitos.

Si partimos de esta premisa, y comparamos la pena inferior del homicidio simple (que es el tramo que cuestionamos) con la de la castración (artículo 395 CP.), de las mutilaciones (396, inciso $1^{\circ} \mathrm{CP}$.), y de las lesiones graves gravísimas (artículo 397 No 1 CP.), que son las que pueden provocar la muerte, es decir, lesiones idóneas para matar o lesiones mortales, podemos comprobar que el juicio cuantitativo de superioridad-inferioridad no puede realizarse a favor del homicidio, pues las penas son iguales o, en el caso de la castración ("muerte en vida"), es superior. Por ello, no afectamos el principio de insignificancia o el non bis in ídem si afirmamos un concurso ideal entre las nombradas lesiones y homicidio.

\section{Casos jurisprudenciales. Confirmación de nUestra tesis}

$\mathrm{Al}$ ya citado y expuesto caso del homicidio frustrado y las lesiones, en el cual la doctrina y jurisprudencia ampliamente mayoritarias aprecian un concurso ideal de delitos, lo que confirma nuestra tesis, hemos de unir el de las lesiones dolosas y homicidio culposo.

La mixtura de dolo inicial en el delito antecedente y culpa en el consecuente da origen a lo que se denomina "delito preterintencional". Nuestra jurisprudencia, desde antiguo, ha estimado que entre ambos hechos existe un concurso ideal de delitos ${ }^{44}$. Y no ha sido óbice a esta declaración la circunstancia que el cuasi-homicidio tiene pena menor que las lesiones dolosas gravísimas, lo que daría pie para, de acuerdo al juicio cuantitativo, apreciar un concurso aparente de leyes penales, amparando el hecho sólo en las lesiones dolosas o, inclusive, si las lesiones fueron menos graves o simplemente graves, el hecho podría haberse cobijado sólo en el cuasidelito de homicidio.

La explicación de esta decisión jurisprudencial no es convincente. Se lee en los manuales al uso que la vida es de superior jerarquía que la integridad corporal y que, por ello, no puede apreciarse un concurso aparente regido

${ }^{44}$ Así, Corte Suprema, sentencia de 21 de abril de 1960, en Revista de Ciencias

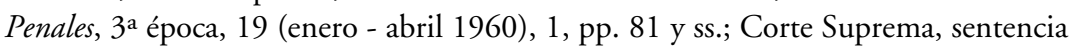
de 17 de agosto de 2005, en Gaceta Jurídica, 302, pp. 180 ss.; y Corte de San Miguel, sentencia de 11 de junio de 2004, rol No 1159-2000. 
por las lesiones ${ }^{45}$. Pero esta explicación choca frontalmente con el sistema de la ley, que asigna mayor pena a las lesiones gravísimas y simplemente graves dolosas o mutilaciones que a la muerte culposa, de manera que si se actuara con consecuencia, las lesiones deberían regir el concurso aparente. A la inversa, si de lesiones menos graves dolosas se trata, el homicidio culposo es más grave, ergo, debería regir el concurso aparente.

¿Por qué el cambio de tratamiento? ¿Acaso tiene relevancia la mixtura de dolo y culpa? No lo creemos, puesto que ella es completamente ajena a los fundamentos del concurso aparente y al de sus principios de solución, que ya hemos mencionado: el dolo y la culpa no inciden en la antijuridicidad objetiva; de manera que sólo nos queda por afirmar que nuestra tesis tiene sustento, porque la jurisprudencia observa concurso ideal de delitos en supuestos en que un solo hecho o conducta produzca lesiones y homicidio.

\section{CONCLUSIONES}

A lo largo del trabajo, hemos demostrado lo siguiente:

a) Si bien es cierto la doctrina y jurisprudencia, ampliamente mayoritaria, aprecian un concurso aparente de leyes penales entre los delitos de lesiones consumadas dolosas y homicidio simple consumado doloso, que algunos solucionan por el principio subsidiariedad tácita y otros por el principio de consunción, no es menos cierto que se incurre en contradicción lógico sistemática cuando se aprecia un concurso ideal en los casos de homicidio preterintencional y homicidio frustrado provocando lesiones, contradicción que afirma nuestra tesis.

b) El concurso aparente entre los citados delitos, que la doctrina patria soluciona por consunción, falla si tenemos en cuenta que no se puede realizar, en nuestro Código Penal, el juicio de ponderación de superioridad entre ambos, en los casos de lesiones mortales (castración, mutilación de miembro importante y lesiones graves gravísimas) y homicidio, porque las penas de tales lesiones no son inferiores a las del homicidio, de manera que nuestra tesis, por tal motivo, también aparece confirmada.

c) En fin, nuestra tesis no se aplica a los homicidios no violentos, es decir, que no lesionan entitativamente; los cometidos por medios morales y por medios indirectos, a los que se les debe aplicar el mínimo de la pena por ser imposible el concurso ideal. Ello, además, es concordante con la menor peligrosidad o capacidad para dañar del medio de comisión em-

${ }^{45}$ Por todos: Politoff, Sergio - Grisolía, Francisco - Bustos, Juan, Derecho Penal, pp. 76-77. 
pleado y con la baja incidencia estadística, que no hace necesario agravar la pena en tales casos.

[Recibido el 28 de agosto de 2009 y aprobado el 19 de abril de 2010].

\section{Bibliografía}

"Actas de la Comisión Redactora del Código Penal".

Anteproyecto de Código Penal, elaborados por los profesores Jean Pierre Matus Acuña y Héctor Hernández Basualto.

Antolisei, Francesco, Manuale di Diritto penale. Parte speciale (4 edición, Milano, 1960), I.

Baumann, Jürgen - Weber, Ulrich, Strafrecht. Allgemeine Teil. Ein Lehbuch (9a edición, Bielefeld, 1985).

Binding, Karl, Handbuch des Strafrechts (Leipzig, 1885), I.

Bockelmann, Paul - Volk, Klaus, Strafrecht. Allgemeine Teil (4a edición, München, 1987).

Bullemore, Vivian - Mackinnon, John, Curso de Derecho penal. Parte especial (2a edición, Santiago, Editorial LexisNexis, 2007), III.

Carrara, Francesco, Programma del corso di Diritto criminale (Lucca, 1869).

Cousiño MaC Iver, Luis, El dolo eventual en la dogmática chilena, en Revista de Ciencias Penales, 27 (1968) 2.

Cury, Enrique, Derecho penal. Parte general (7a edición ampliada, Santiago, Ediciones Universidad Católica de Chile, 2005).

Del Rosal, Juan, Lecciones de Derecho Penal (Valladolid, 1953).

Deutscher Bundestag 5. Walhperiode 1965-1969, Protokolle des Sonderausschu für die Strafrechtsreform.

Etcheverry, Alfredo, Derecho penal. Parte general (3a edición, Santiago, Editorial Jurídica de Chile, 1998), II.

ETCHEVERrY, Alfredo, El concurso aparente de leyes penales (Santiago, Editorial Jurídica de Chile, sin fecha).

Frank, Reinhard, Das Strafgesetzbuch für das Deutsche Reich (18 a edición, Tübingen, 1931).

Garrido Montt, Mario, Derecho penal. Parte especial (Santiago, Editorial Jurídica de Chile, 2001), III.

GEERDS, Friederich, Zur Lehre von der Konkurrenz im Strafrecht (Hamburg, 1961).

GössEL, Karl, Besprechung über I. Puppes Idealkonkurrenz und Einzelverbrechen, en Goltdammer Archiv fiir Strafrecht (1981).

HabermaAs, Frank, Die Ideale Konkurrenz der Delikte (Stuttgart, 1882).

HoniG, Richard, Straflose vor- und Nachtat (Leipzig, 1927).

JaKoBs, Günther, Strafrechts, Allgemeine Teil. Die Grundlagen und die Zurechnungslehre ( $2^{a}$ edición, Berlin, 1991).

JesCHeck, Hans-Heinrich, Lehrbuch des Strafrechts. Allgemeine Teil (4a edición, Berlin, 1988).

Matus Acuña, Jean Pierre, Comentario preliminar a los artículos 74 y 75 del Código (Santiago, Editorial Jurídica de Chile, 2002), I. 
Matus Acuña, Jean Pierre, La ley penal y su interpretación (Santiago, Editorial Jurídica Congreso, 1994).

Mayer, Max Ernst, Derecho Penal. Parte general (traducción y notas de Politoff, Sergio, Montevideo - Buenos Aires, Editorial B de F, 2007).

MAYER, Max Ernst. Der allgemeine Teil des Deutsche Strafrechts. Lehrbuch (Heidelberg, 1915).

Merkel, Adolph, Handbuch des deutschen Strafrechts (Berlin, 1877), IV.

Mezger, Edmund. Strafrecht. Ein Lehrbuch (3a edición, Berlin - München, 1949).

Mir Puig, Santiago, Derecho penal. Parte general (3a edición, Barcelona, 1990).

Novoa Monreal, Eduardo, Delito de homicidio y la intención de matar, en Revista de Ciencias Penales, 8 (1945).

Отто, Harro. Grundkurs Strafrecht (4a edición, Berlin, 1992).

Politoff, Sergio - Grisolía, Francisco - Bustos, Juan, Derecho penal.

PRAmbs, Claudio, ¿Qué es el dolo penal y qué es el error penal? en Revista de Derecho y Ciencias Penales, 10 (Universidad San Sebastián, 2008).

Prambs, Claudio, El tipo de culpabilidad en el Código Penal chileno: Una visión sistemática, normativa y positiva (Santiago, Editorial Metropolitana, 2005).

Puig Peña, Federico. Colisión de normas penales: concurso aparente de leyes punitivas (Barcelona, 1955).

Puppe, Ingeborg, Exklusivität von Tatbeständen, en Juristische Ausbildung (1984).

Quintero, Gonzalo - Morales, Fermín - Prats, José, Manual de Derecho penal. Parte general (Pamplona, Editorial Aranzadi, 1999).

Reichardt, Carl, Kurzgefaßtes Lehrbuch des deutschen Strafrechts (Karlsruhe, 1912).

Rodríguez Devesa, José María, Derecho penal español. Parte general (1 $1^{a}$ edición, reimpresión, Madrid, 1971).

Rodríguez Mourullo, Gonzalo, Derecho penal. Parte general (Madrid, 1978).

Roxin, Claus, Derecho penal. Parte general. Fundamentos. La estructura de la teoría del delito (traducción y notas de Luzón Peña, D. y otros, Madrid, Civitas, 1997), I.

SCHMidHÄUSER, Eberhard, Strafrecht. Allgemeine Teil. Lehrbuch (Tübingen, 1975).

Sснмітт, Rodolf, Vorsätzliche Tötung und Vorsätzliche Körperverletzung: Eine systematische Untersuchung im Anschlu $\beta$ an BGHSt 16, 122, en Juristische Zeitung (1962).

SCHÖNKE, Adolf - SCHrÖDER, Horst - STree, Walter, Strafgesetzbuch Kommentar (24a edición, München, 1991).

Wessels, Johannes, Strafrechts. Allgemeine Teil (23a edición, Heidelberg, 1993).

WiLHELM, Allgemeine Strafrechtslehre (3a edición, Berlin, 1955). 